\title{
Effects of nutrient and water restriction on thermal tolerance: A test of mechanisms and hypotheses
}

\author{
Katherine A. Mitchell ${ }^{\mathrm{a}, *}$, Leigh Boardman ${ }^{\mathrm{a}, 1}$, Susana Clusella-Trullas ${ }^{\mathrm{b}}$, John S. Terblanche ${ }^{\mathrm{a}}$ \\ a Department of Conservation Ecology and Entomology, Stellenbosch University, South Africa \\ b Centre for Invasion Biology, Department of Botany and Zoology, Stellenbosch University, South Africa
}

\section{A R T I C L E I N F O}

\section{Keywords:}

Cross-tolerance

Heat knockdown

Chill coma recovery

Diptera

Tephritidae

Heat shock proteins

\begin{abstract}
A B S T R A C T
Nutritional deprivation or desiccation can influence thermal tolerance by impacting the insects' ability to evaporatively cool, maintain cell membrane integrity and conduct protective or repair processes. Recovery from chilling is also linked to the re-establishment of iono- and osmo-regulatory homeostasis. Here, using Mediterranean fruit fly (Ceratitis capitata, Diptera: Tephritidae), we manipulated water and nutrient availability to test the mechanistic expectation that changes in whole organism lipid and water content can elicit variation in cold or heat tolerance (scored as chill coma recovery time and heat knockdown time). We measured body condition (body water and lipid content) as well as heat shock protein 70 gene (hsp70) and protein (HSP70) levels. A significant reduction in body water content with water restriction did not translate into differences in chill coma recovery. When nutrient restriction was coupled with water deprivation, this resulted in a significant reduction $(-54 \%)$ of heat knockdown time in females but male flies were unaffected. There was no evidence for an $h s p 70$ or HSP70 response under any of the stress treatments and therefore no correlation with heat or cold tolerance. Heat hardening decreased all hsp levels. Therefore, although body water and total body lipid content differed between the treatment groups, the contribution of these factors to thermal tolerance was inconsistent with mechanistic expectations in heat knockdown time and insignificant for chill coma recovery. These results therefore highlight that the effects of resource restriction on thermal limits in insects are mechanistically more complex than previous models of stress resistance have suggested.
\end{abstract}

\section{Introduction}

Traits of thermal tolerance or resistance are strongly correlated with insect species' geographic distributions (reviewed in Addo-Bediako et al., 2000), and assessing the factors influencing these traits in the field is important (e.g. Sinclair and Roberts, 2005; Cooper et al., 2008; Terblanche et al., 2011). Most studies use laboratory-based methodology to control for a host of intrinsic and extrinsic factors that can influence thermal tolerance estimates, such as recent thermal history (e.g. season, acclimation), age or sex (e.g. Fischer et al., 2010). The impact of body condition on tolerance estimates is typically not the subject of investigation (but see e.g. Terblanche et al., 2008; Overgaard et al., 2012). As the temporary deprivation of food and/or water can have downstream impacts on organismal performance and fitness, tolerating these stressors is essential for insects in heterogeneous landscapes. Mathematical models have also highlighted how thermal traits may be influenced by nutritional and water status at the organismal level (Kearney et al., 2013). Complex interactions and fitness trade-offs occur between stressors in at least some instances (reviewed in Hoffmann et al., 2003; Mellanby, 1932; Bubliy et al., 2012a, b; Overgaard et al., 2012; Kellermann et al., 2013; Karl et al., 2014; Boardman et al., 2015; Scharf et al., 2016). The different approaches typically employed, and range of stressors considered may elicit very different underlying physiological processes, or similar trait responses may arise from distinctly different mechanisms. Thus, determining the mechanistic underpinnings of multi-stressor responses to changing body condition is a crucial avenue for forecasting species responses to changing environments.

There are at least three major expectations for how stress resistance may respond under changing nutritional or hydration conditions at the organismal level. First, the organism may already have the necessary cellular biochemistry in place to fully withstand the stress, and therefore no effect would be detected on thermal tolerances. Second, exposure to stress (e.g. food or water deprivation) may result in upregulation of protective (or repair) mechanisms that allows the organisms to better withstand subsequent thermally stressful conditions. Finally,

\footnotetext{
* Corresponding author at: Department of Conservation Ecology and Entomology, Stellenbosch University, Private Bag X1, Matieland 7602, South Africa.

E-mail address: mitchell.katherine@gmail.com (K.A. Mitchell).

${ }^{1}$ Current address: Department of Entomology and Nematology, University of Florida, Gainesville, USA.
} 
biochemical or physiological responses may be upregulated but are insufficient to compensate for the subsequent thermal stress. Predictable trait responses can be generated to differentiate among these possibilities.

Desiccation prior to a heat or cold tolerance assay would generally be expected to reduce overall thermal tolerance by restricting available water resources that underlie multiple physiological traits (reviewed in Zera and Harshman, 2001). However, some studies have found a positive association between prior desiccation stress and heat tolerance (e.g. Benoit et al., 2009; Bubliy et al., 2012a), largely attributed to the upregulation of heat shock proteins (Hsps) that act as molecular chaperones for damaged proteins (Feder and Hofmann, 1999). However, the association is equivocal depending on stress type and exposure duration (e.g. Feder et al., 1992; Silbermann and Tatar, 2000; Boardman et al., 2013; Sørensen et al., 2013). Desiccation has been associated with improved cold hardiness by potentially increasing the osmolality of the tissue, which in turn, decreases the temperature at which the organism freezes (supercooling point; reviewed in Zachariassen, 1985). Cryoprotective dehydration, whereby an organism loses water during cold stress to avoid ice formation in tissues, is an important low temperature survival strategy found in many insects (e.g. Sørensen and Holmstrup, 2011; reviewed in Chown and Terblanche, 2006). However, if the organism does not freeze, then this increase in osmolality may detrimentally affect the individuals' ability to regain ion homeostasis, the latter of which is the major hypothesis describing insects' inability to recover from chill coma (e.g. Coello Alvarado et al., 2015; Olsson et al., 2016, reviewed in Overgaard and MacMillan, 2017).

Nutritional stress might influence thermal tolerance primarily through reductions in body lipid levels. Lipid levels and the composition thereof (e.g. long vs. short chains, number of double vs. single bonds) are thought to underpin the link between starvation and thermal tolerance in Drosophila (e.g. Hoffmann and Harshman, 1999; Hoffmann et al., 2005). For example, a negative association is found between starvation resistance and cold tolerance due to the importance of lipids in both traits (e.g. Hoffmann et al., 2005). Reductions in lipid levels are generally associated with starvation across all organisms (McCue, 2010) but may result in increased water uptake (e.g. Raubenheimer and Gäde, 1993) which can be beneficial for improving heat tolerance by increasing the water stores available for evaporative cooling or generally withstanding desiccation stress (Chown and Nicholson, 2004).

Here we provide a systematic, comprehensive assessment of these potential mechanisms that have been hypothesised to underlie the influence of water and nutritional status on thermal tolerance using the Mediterranean fruit fly, Ceratitis capitata (Wiedemann) (Diptera: Tephritidae). As a global agricultural pest there is considerable interest in better understanding its basal and plastic climatic stress resistance, and the underlying mechanisms thereof (De Meyer et al., 2008; Malacrida et al., 2007; Nyamukondiwa et al., 2010). Previous studies have measured chill coma recovery time and heat knockdown time (Weldon et al., 2011), shown a pronounced decrease in heat tolerance (measured as CTmax) following prior starvation (Nyamukondiwa and Terblanche, 2009) and plastic responses to prior thermal exposures (Nyamukondiwa et al., 2010) that were attributed to variation in $h s p 70$ mRNA expression (Kalosaka et al., 2009, but see Pujol-Lereis et al., 2014). We exposed C. capitata to a full factorial experimental design of long term (i.e. several days as adults) restriction of nutrients, water and the combined restriction of both nutrient and water and then assayed chill coma recovery time and heat knockdown time. We also estimated body water and body lipid amounts, and the relative amount of mRNA hsp70, HSP70 protein and total protein concentration to explain any potential thermal tolerance responses. We predicted that restricting water or nutrient levels would have a detrimental effect on heat tolerance and, by contrast, be beneficial for cold tolerance. Furthermore, it can be predicted that if thermal tolerance is set in some mechanistic way by an organism's body condition, then combined stressors of nutrient and water restriction should have a greater reduction on thermal limits than either stressor applied individually, and these latter should reduce thermal limits more than a control or reference group. Heat tolerance is likely to be impacted by reduced water stores by limiting evaporative cooling and/or reducing the pool of water available to survive prolonged stress. Nutrient restriction may also be detrimental for heat tolerance by reducing the amount of stored lipids that can be metabolised for water. The change in saturation of cell membranes caused by reduced nutrient levels would be beneficial for cold tolerance. Reduced water levels would benefit cold tolerance by reducing the formation of ice within the tissue. However, if the nutrient restriction results in an increased uptake in water, heat tolerance may benefit from increased structural integrity of cell membranes i.e. through lipid saturation, and more available body water for evaporative cooling. Cross-tolerance may also be detected if prior depletion of nutrients or water results in heat shock protein production.

\section{Materials and methods}

\subsection{Experimental treatments}

Ceratitis capitata (Diptera: Tephritidae) pupae were obtained from laboratory stocks maintained in large laboratory cultures at Citrus Research International (CRI) at Nelspruit, South Africa that have been established for c. 15 years (or \pm 180 generations). Colonies were last partially substituted with wild-caught flies in 2011 (A. Manrakhan, pers. comm.). One-day old adults were separated by sex into groups of 10 flies, placed into ventilated $5 \mathrm{~L}$ plastic containers at $25^{\circ} \mathrm{C} \pm 1{ }^{\circ} \mathrm{C}$ (LE-509 incubator, MRC Lab Instruments, Holon, Israel) with a $12 \mathrm{~h}$ : $12 \mathrm{~h}$ diurnal cycle and provided food and water ad libitum as sugar crystals and $\mathrm{dH}_{2} \mathrm{O}$-moistened cotton wool. A protein source was not provided as the hydrolysed protein absorbed moisture, influencing the water restricted and nutrient + water restricted treatments. As the flies being examined were young, i.e. $<5$ days of age, and examined prior to peak egg production age (approximately 10 days of age; Carey et al., 1998), the impacts of not providing a protein resource are likely to be minimal. The following day, flies were divided into four experimental treatments for $72 \mathrm{~h} ; 1$ ) food and water ad libitum (control), 2) no food but water (Restricted nutrient $_{\text {t }}$ ), 3) food but no water $\left(\right.$ Restricted $_{\text {water }}$ ), and

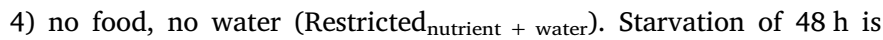
known to result in the complete emptying of the gut contents in Tephritids (Shelly and Kennelly, 2003; Nyamukondiwa and Terblanche, 2009) whereas exposure to $>72 \mathrm{~h}$ without water is known to be lethal in C. capitata (Weldon et al., 2016). Humidity was maintained at c. $76 \%$ R.H. by the inclusion of $250 \mathrm{~mL}$ jars of saturated $\mathrm{NaCl}$ solution (covered by mesh; Winston and Bates, 1960). To be confident that the individuals in the treatments with food and/or water were satiated prior to testing, food and water (but not humidity) sources were removed for approximately $10 \mathrm{~h}$ and reintroduced $2 \mathrm{~h}$ prior to testing. The flies were then directly observed to have consumed food or water before collection and randomly assigned to experimental assays.

\subsection{Thermal tolerance assays}

Protocols for assaying chill coma recovery and heat knockdown time were conducted following Weldon et al. (2011). Briefly, individual flies were removed from their respective treatments (at 4-days of age), weighed to $0.1 \mathrm{mg}$ (NewClassic MF MS104S, max $120 \mathrm{~g}$, Mettler Toledo, Switzerland) to determine wet mass and placed individually in $7.5 \mathrm{~mL}$ glass vials with push cap lids. For chill coma recovery, these vials were then placed inside a water-tight plastic bag and submerged into a programmable circulating bath (cw410-wl, Huber, Germany) containing ethanol and exposed to $0 \pm 0.5{ }^{\circ} \mathrm{C}$ for $1 \mathrm{~h}$. Following removal, the flies were maintained in the vials at $25 \pm 0.5{ }^{\circ} \mathrm{C}$ on a thermal stage and monitored to observe the time that individuals took to regain the ability to stand (recorded as chill coma recovery time). 
This thermal stage was constructed of an enclosed Perspex box situated atop an aluminium base beneath which fluid containing $50 \%$ propylene glycol: water solution was circulated using a programmable, circulating bath (cw410-wl, Huber, Germany). For heat knockdown time, the time taken to succumb to heat stress (i.e. the loss of righting response), following acute exposure to $44{ }^{\circ} \mathrm{C} \pm 0.3{ }^{\circ} \mathrm{C}$ on the thermal stage was recorded. Individual flies within sealed vials were placed upon the thermal stage. In both assays, one empty vial contained a thermocouple (K-type, 36 standard wire gauge, Omega Engineering Inc., Stamford, CT, USA) attached to a digital thermometer (Fluke 54 II, Fluke Corporation, Everett, WA, USA) to record temperature throughout the assay and 20 flies of each sex per experimental treatment were tested, split evenly across three replicates. As only 8 males survived the Restricted $_{\text {nutrient }}+$ water pre-treatment, these flies were split evenly between the two thermal tolerance assays. This yielded a total $n=144$ for chill coma recovery and heat knockdown time each. Data were standardised relative to the control group for each replicated assay to reduce skewness of distribution.

\subsection{Body water and lipid content}

A randomly chosen subset of 15 individual flies per trait, sex and

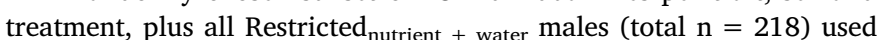
in the thermal tolerance assays were reweighed directly after thermal stress testing before being placed into $0.5 \mathrm{~mL}$ PCR reaction tubes with the lids open in an oven (IncoTherm S, Labotec, South Africa) set at $40{ }^{\circ} \mathrm{C}$ for $72 \mathrm{~h}$. Flies were then weighed again (dry mass) and the difference to wet mass was determined as the body water content for each fly. The same flies were then used to determine body lipid content by washing individual flies three times in a 1:1 mixture of chloroform:methanol to extract whole lipids (following e.g. Boardman et al., 2013). The wash solution was replaced every $24 \mathrm{~h}$ for 3 days to ensure complete removal of soluble lipids before samples were air dried and weighed again (lean mass). The difference in mass between the dried and lipid-digested (lean) mass provided the body lipid content (Hoffmann et al., 2005). The measured water and lipid content of each fly was standardised relative to the lean (i.e. divided by dried and lipiddigested) body mass of the individual to account for body size differences between individuals.

\subsection{Hsp70 mRNA and protein quantification}

To determine if the Restricted nutrient, $_{\text {Restricted }}$ water and Restricted $_{\text {nutrient }}+$ water pre-treatments involved the induction of heat shock proteins, 10 groups of two male or female flies from each of the four treatment groups were snap frozen in liquid nitrogen immediately following the 72-hour stress period. An additional hardening treatment was also added, with control group flies being exposed to $39^{\circ} \mathrm{C}$ for $1 \mathrm{~h}$ prior to being snap frozen, as this has been shown previously to induce a strong hsp70 mRNA response in C. capitata (Kalosaka et al., 2009). These samples were then stored at $-80^{\circ} \mathrm{C}$ until protein quantification or mRNA expression could be conducted (typically $<$ two weeks).

Three biological replicates consisting of two flies for each treatment and sex (total $\mathrm{n}=30$ were assayed for $h s p 70$ mRNA expression. RNA was extracted using the RNeasy mini-kit (Qiagen), with the addition of $\beta$-mercaptoethanol in the homogenizing stage following the manufacturer's instruction. The concentration of extracted RNA was then quantified using a Nanodrop ${ }^{\circledR}$ ND-1000 spectrophotometer (ThermoScientific, Wilmington, DE) using the RNA setting (260/ $280 \mathrm{~nm}$ wavelength). Dilutions of $30 \mathrm{ng} / \mu \mathrm{L}$ in RNAse-free water were then used for reverse transcription to cDNA using the Quantitect ${ }^{\circledR}$ Reverse Transcription kit (Qiagen). Primers for hsp70 (GenBank accession number Y08955.1; Papadimitriou et al., 1998) and the two housekeeping genes, CcRpL13 and CcActin (GenBank accession numbers FG085984.1 and FG081771.1, respectively; Scolari et al., 2012) were designed using Primer3 Plus web version (http://primer3plus.com) before being checked for specificity across all $C$. capitata sequences using Primer-BLAST (www.ncbi.nlm.nih.gov/tools/primer-blast). Chosen primers were ( $\left.5^{\prime}-3^{\prime}\right)$; $h s p 70$ F-AAACTGAGTGAGCGGGAGAA, RTAGGTCCAGTGTGACCACCA; RpL13 F-GACGAATAGGGCCGTTGTTA, R-AGCACGGAAGTGGTATGGAC; Actin F-CAATTGTGCACAGGAAATGC, R-ACTCGTCCAAAGACGAATGG. RT-PCR was conducted with Qiagen QuantiFast SYBR ${ }^{\circledR}$ Green PCR kit using an Applied Biosystems StepOnePlus $^{\mathrm{TM}}$ 96-well system. Following a 5-minute initial heating step at $95{ }^{\circ} \mathrm{C}$, cycling parameters of $10 \mathrm{~s}$ denaturation at $95{ }^{\circ} \mathrm{C}, 30 \mathrm{~s}$ annealing/ extension at $60^{\circ} \mathrm{C}$ for 40 cycles were used. Fluorescence readings were made at the end of each cycle and specificity of amplified product determined by melting curve analysis. Three technical replicates were included for each sample and gene combination, with the mean values being used for analysis. Biological replicates of each treatment and sex combination were included on each plate as well as a common standard sample to standardise across runs. As expression data for CcActin and $C c R p L$ were similar, the relative expression of $h s p 70$ to $C c R p L 13$ was used for further analysis.

Total protein and HSP70 levels were measured in five biological replicates of two flies per sex and treatment (total $n=50$ ). Samples were thawed from $-80{ }^{\circ} \mathrm{C}$ and weighed on a microbalance before total proteins were extracted by homogenizing each sample in $80 \mu \mathrm{L}$ PBS buffer with anti-protease cocktail. The homogenate was centrifuged and the protein concentration of the supernatant quantified using a BCA assay kit (Pierce, Thermo Fischer Scientific Inc., USA). Western blotting was performed following Clusella-Trullas et al. (2014) to determine specificity of binding to the $70 \mathrm{kDa}$ HSP protein product in $C$. capitata and also a positive control (HeLa cytoplasmic lysate, Abcam, Cambridge, UK). The HSP70 protein antigen binding was specific for $C$. capitata, as evidenced by the Western blot (Fig. S1, supplementary material). HSP70 protein standard enzyme linked immuosorbent assay (ELISA) was performed following Boardman et al. (2013) using monoclonal anti-heat shock protein 70 antibody produced in mouse (clone BRM-22, 1:5000, Sigma \#H5147) as the primary antibody and HRP-conjugated rabbit anti-mouse IgG (1:20,000, Abcam \#6728) as the secondary antibody. The primary antibody detects both the constitutive (HSP73) and inducible (HSP72) forms of HSP70 protein. Biological replicates were run in duplicate within plates and absorbance estimates standardised relative to the blank sample and plate grand mean following Sørensen et al. (2013). All experimental treatments were represented on each plate. Plates were duplicated to account for technical variation. Total protein concentration was standardised relative to body mass to remove the significant association (GLM, Gaussian distribution, identity link function, Wald's $\chi^{2}=0.193 \pm 0.052 \mathrm{SE}, \mathrm{t}=3.724$, $\mathrm{p}>0.001)$.

\subsection{Statistical analysis}

The effects of experimental treatment and sex on chill coma recovery and heat knockdown time, standardised relative to the control group, as well as their subsequent body water and body lipid content estimates, were assessed using a generalized linear model (GLM) with a Gaussian distribution and identity link function in R 3.1.0 (R core team, 2013). Models were checked for overdispersion and assumptions were met except for body water content that was log-transformed to account for overdispersion. The effect of experimental treatment and sex on the fold difference for $h s p 70$ mRNA, together with the absorbance of HSP70 protein and total protein amount (relative to body mass) were determined using a GLM as above.

\section{Results}

\subsection{Thermal tolerance}

There was no significant effect of the nutrient or water restriction on chill coma recovery time in $C$. capitata (Fig. 1A, Table 1 ; means \pm SE 

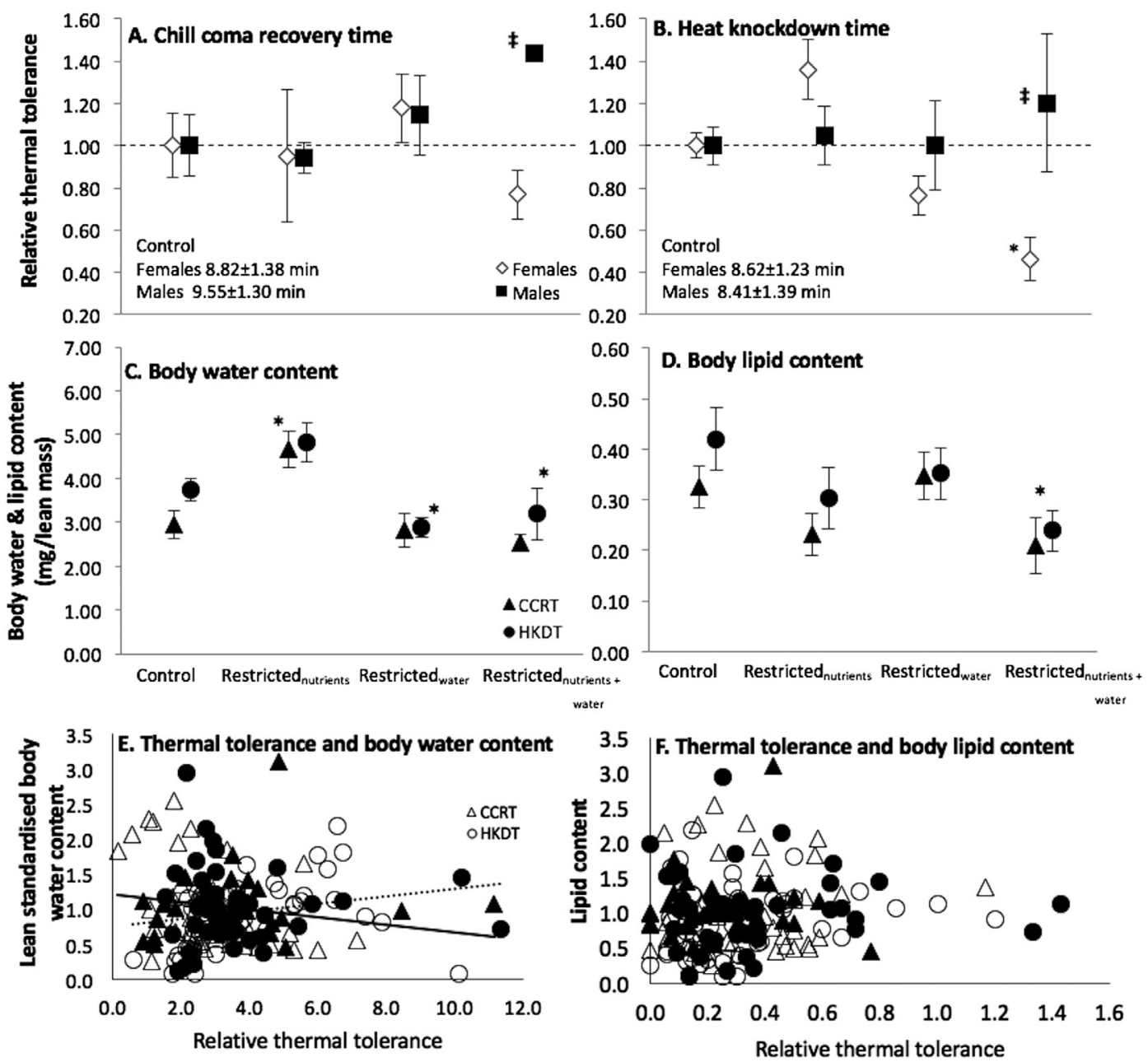

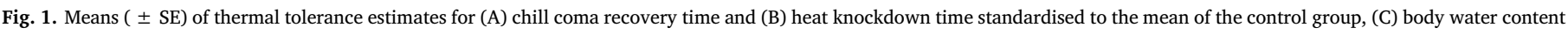

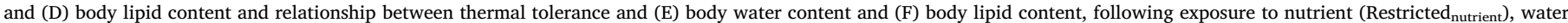

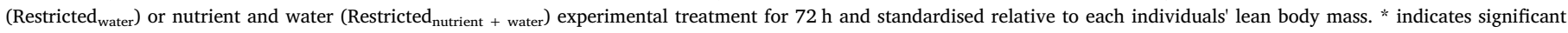

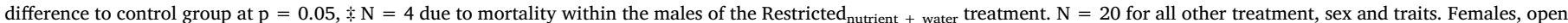

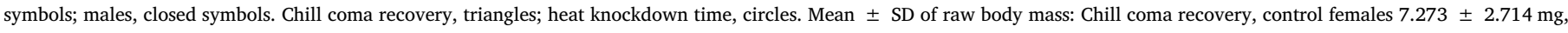

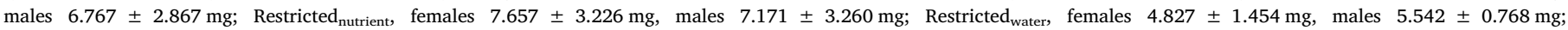

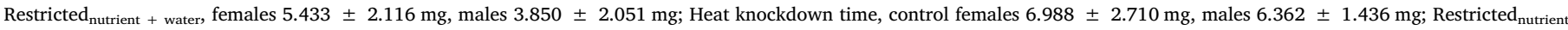

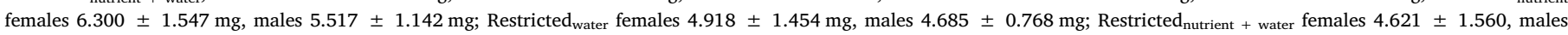
$4.420 \pm 1.312 \mathrm{mg}$

chill coma recovery of control groups: females, $8.82 \pm 1.38 \mathrm{~min}$; males, $9.55 \pm 1.30 \mathrm{~min})$. There were also no overall differences in chill coma recovery between the sexes in this trait (Fig. 1A, Table 1). In contrast, heat knockdown time was significantly influenced by experimental treatments (Table 1), (means \pm SE heat knockdown time of control groups: females, $8.62 \pm 1.23 \mathrm{~min}$; males, $8.41 \pm 1.39 \mathrm{~min}$ ). Females showed a more pronounced response to the prior stress exposure than males (Fig. 1B), where Restricted nutrient $_{\text {treatment showed a }}$ non-significant trend towards increased heat tolerance in females, whereas Restricted water $_{\text {and }}$ Restricted $_{\text {nutrient }+ \text { water decreased it }}$ (Fig. 1B). However, the heat knockdown time for Restricted ${ }_{\text {water }}$ flies or Restricted $_{\text {water }} \times$ sex interaction was not significantly different from

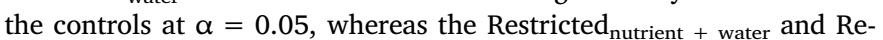
stricted $_{\text {nutrient }}+$ water $\times$ sex interactions were (Table 1 ).

\subsection{Body water and body lipid content}

Body water content relative to body size following chill coma recovery and heat knockdown time varied little between the two measures (Fig. 1C). There was increased water content in the Restricted $_{\text {nutrient }}$ treatment; however, this difference was only significant for chill coma recovery (Fig. 1C, Table 1). The Restricted water $_{\text {and Re- }}$ stricted $_{\text {nutrient }}+$ water treatments significantly reduced the amount of body water content in the heat knockdown time relative to controls (Fig. 1D; Table 1). The relative body lipid content varied little between treatment and traits, with the Restricted ${ }_{\text {nutrient }}+$ water treatment reducing body lipid content levels in heat knockdown time scored flies (Fig. 1D; Table 1).

The association between standardised tolerance, body water content, sex and the interaction across both traits was highly significant. Both body water content and sex had a negative association with chill coma recovery time but a positive association for heat knockdown time (Table 2). The negative association of body water with chill coma recovery appears largely due to many individuals with limited thermal tolerance i.e. value $<2$, but high body water content (Fig. 1E). By contrast, the water content in flies exposed to heat knockdown time is more similarly between individuals with different heat tolerance. The relationship of standardised tolerance with body lipid content and sex was not significant for either heat knockdown time or chill coma recovery (Table 2, Fig. 1F). 
Table 1

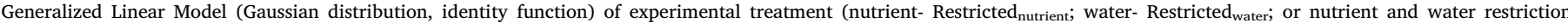

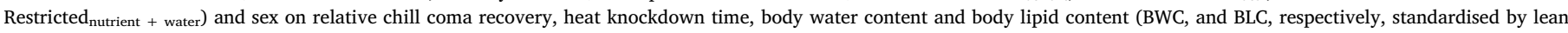
body mass) in $C$. capitata. Factors in bold indicate significance at $\mathrm{p}=0.05$. BWC was log-transformed to account for overdispersion.

\begin{tabular}{|c|c|c|c|c|c|c|c|}
\hline Trait & & AIC & Factor & Wald's $\chi^{2}$ & SE & t value & $\mathrm{p}$ \\
\hline \multirow[t]{18}{*}{ Chill coma recovery time } & \multirow[t]{8}{*}{ Overall } & \multirow[t]{8}{*}{266.08} & Intercept & 1.000 & 0.148 & 6.756 & $<0.001$ \\
\hline & & & Restricted $_{\text {nutrient }}$ & -0.048 & 0.263 & -0.185 & 0.854 \\
\hline & & & Restricted $_{\text {water }}$ & 0.179 & 0.209 & 0.855 & 0.396 \\
\hline & & & Restricted $_{\text {nutrient }}+$ water & -0.232 & 0.277 & -0.839 & 0.405 \\
\hline & & & Sex & 0.001 & 0.241 & -0.001 & 0.999 \\
\hline & & & Restricted $_{\text {nutrient }} \times$ sex & -0.010 & 0.390 & -0.027 & 0.979 \\
\hline & & & Restricted $_{\text {water }} \times$ sex & -0.033 & 0.328 & -0.101 & 0.919 \\
\hline & & & Restricted $_{\text {nutrient }}+$ water $\times$ sex & 0.673 & 0.527 & 1.277 & 0.206 \\
\hline & \multirow[t]{5}{*}{ Log lean body water content } & \multirow[t]{5}{*}{144.11} & Intercept & 0.874 & 0.138 & 6.319 & $<0.001$ \\
\hline & & & Restricted $_{\text {nutrient }}$ & 0.531 & 0.209 & 2.539 & 0.013 \\
\hline & & & Restricted $_{\text {water }}$ & -0.144 & 0.174 & -0.829 & 0.410 \\
\hline & & & Restricted $_{\text {nutrient }}+$ water & 0.003 & 0.254 & 0.011 & 0.991 \\
\hline & & & Sex & 0.157 & 0.149 & 1.055 & 0.295 \\
\hline & \multirow[t]{5}{*}{ Lean body lipid content } & \multirow[t]{5}{*}{-61.05} & Intercept & 0.290 & 0.034 & 8.557 & $<0.001$ \\
\hline & & & Restricted $_{\text {nutrient }}$ & -0.063 & 0.051 & -1.225 & 0.225 \\
\hline & & & Restricted $_{\text {water }}$ & 0.016 & 0.043 & 0.384 & 0.702 \\
\hline & & & Restricted $_{\text {nutrient }}+$ water & -0.094 & 0.062 & -1.515 & 0.134 \\
\hline & & & Sex & -0.054 & 0.037 & -1.465 & 0.148 \\
\hline \multirow[t]{18}{*}{ Heat knockdown time } & \multirow[t]{8}{*}{ Overall } & \multirow[t]{8}{*}{176.76} & Intercept & 1.000 & 0.088 & 11.383 & $<0.001$ \\
\hline & & & Restricted $_{\text {nutrient }}$ & 0.244 & 0.124 & 1.964 & 0.051 \\
\hline & & & Restricted $_{\text {water }}$ & -0.179 & 0.126 & -1.424 & 0.156 \\
\hline & & & Restricted $_{\text {nutrient }+ \text { water }}$ & -0.453 & 0.120 & -3.768 & $<0.001$ \\
\hline & & & Sex & 0.000 & 0.122 & 0.000 & 1.000 \\
\hline & & & Restricted $_{\text {nutrient }} \times$ sex & -0.219 & 0.175 & -1.253 & 0.212 \\
\hline & & & Restricted $_{\text {water }} \times$ sex & 0.047 & 0.175 & 0.269 & 0.789 \\
\hline & & & Restricted $_{\text {nutrient }+ \text { water }} \times$ sex & 0.460 & 0.182 & 2.530 & 0.012 \\
\hline & \multirow[t]{5}{*}{ Log lean body water content } & \multirow[t]{5}{*}{110.18} & Intercept & 1.296 & 0.095 & 13.681 & $<0.001$ \\
\hline & & & Restricted $_{\text {nutrient }}$ & 0.219 & 0.121 & 1.802 & 0.075 \\
\hline & & & Restricted $_{\text {water }}$ & -0.271 & 0.120 & -2.258 & 0.027 \\
\hline & & & Restricted $_{\text {nutrient }+ \text { water }}$ & -0.341 & 0.130 & -2.629 & 0.010 \\
\hline & & & Sex & -0.042 & 0.091 & -0.464 & 0.644 \\
\hline & \multirow[t]{5}{*}{ Lean body lipid content } & \multirow[t]{5}{*}{-47.89} & Intercept & 0.319 & 0.040 & 7.943 & $<0.001$ \\
\hline & & & Restricted $_{\text {nutrient }}$ & -0.085 & 0.051 & -1.658 & 0.101 \\
\hline & & & Restricted $_{\text {water }}$ & -0.044 & 0.051 & -0.868 & 0.388 \\
\hline & & & Restricted $_{\text {nutrient }}+$ water & -0.119 & 0.055 & -2.168 & 0.033 \\
\hline & & & Sex & 0.022 & 0.038 & 0.581 & 0.563 \\
\hline
\end{tabular}

\section{3. hsp70 mRNA, HSP70 and total protein}

Expression levels of $h s p 70$ mRNA and HSP70 protein levels showed no statistically significant response immediately following the 72-hour experimental treatment regime applied and no significant variation between the sexes (Fig. 2A and B, Table 3). However, the $39^{\circ} \mathrm{C}$ hardening treatment significantly reduced mRNA and protein $\mathrm{Hsp70}$ levels (Fig. 2A and B, Table 3). Once body mass was accounted for, total protein amount varied, with significantly less protein in the
Restricted $_{\text {nutrient }}$ and hardened experimental treatments (Fig. 2C, Table 3).

\section{Discussion}

Lipid amount and composition, and associated water availability, feature most prominently among the list of implicated mechanisms of cross-tolerance with stress resistance, along with the generic stress response of heat shock proteins. Cross-tolerance, or protective

Table 2

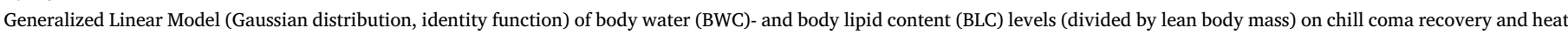
knockdown time in Ceratitis capitata. Factors in bold indicate significance at $\mathrm{p}=0.05$. Body water content was log-transformed to account for overdispersion.

\begin{tabular}{|c|c|c|c|c|c|c|}
\hline Trait & AIC & Factor & Wald's $\chi^{2}$ & SE & t value & $\mathrm{p}$ \\
\hline \multirow[t]{8}{*}{ Chill coma recovery time } & 117.17 & Intercept & 1.417 & 0.132 & 10.712 & $<0.001$ \\
\hline & & Log lean body water content & -0.433 & 0.117 & -3.721 & $<0.001$ \\
\hline & & Sex & -0.557 & 0.239 & -2.333 & 0.023 \\
\hline & & $\log B W C \times \operatorname{sex}$ & 0.628 & 0.197 & 3.185 & 0.002 \\
\hline & 131.17 & Intercept & 0.91706 & 0.17172 & 5.341 & $<0.001$ \\
\hline & & Log lean body lipid content & 0.38668 & 0.54299 & 0.712 & 0.479 \\
\hline & & Sex & 0.09838 & 0.26091 & 0.377 & 0.707 \\
\hline & & $\log B L C \times \operatorname{sex}$ & -0.12361 & 0.92509 & -0.134 & 0.894 \\
\hline \multirow[t]{8}{*}{ Heat knockdown time } & 133.79 & Intercept & 0.2805 & 0.1751 & 1.602 & 0.113 \\
\hline & & Log lean body water content & 0.5006 & 0.1354 & 3.696 & $<0.001$ \\
\hline & & Sex & 0.8227 & 0.2877 & 2.86 & 0.005 \\
\hline & & $\log B W C \times \operatorname{sex}$ & -0.5555 & 0.226 & -2.458 & 0.016 \\
\hline & 145.66 & Intercept & 0.7411 & 0.1337 & 5.544 & $<0.001$ \\
\hline & & Log lean body lipid content & 0.5228 & 0.4357 & 1.2 & 0.233 \\
\hline & & Sex & 0.3011 & 0.1958 & 1.537 & 0.128 \\
\hline & & $\log B L C \times \operatorname{sex}$ & -0.5384 & 0.5995 & -0.898 & 0.372 \\
\hline
\end{tabular}



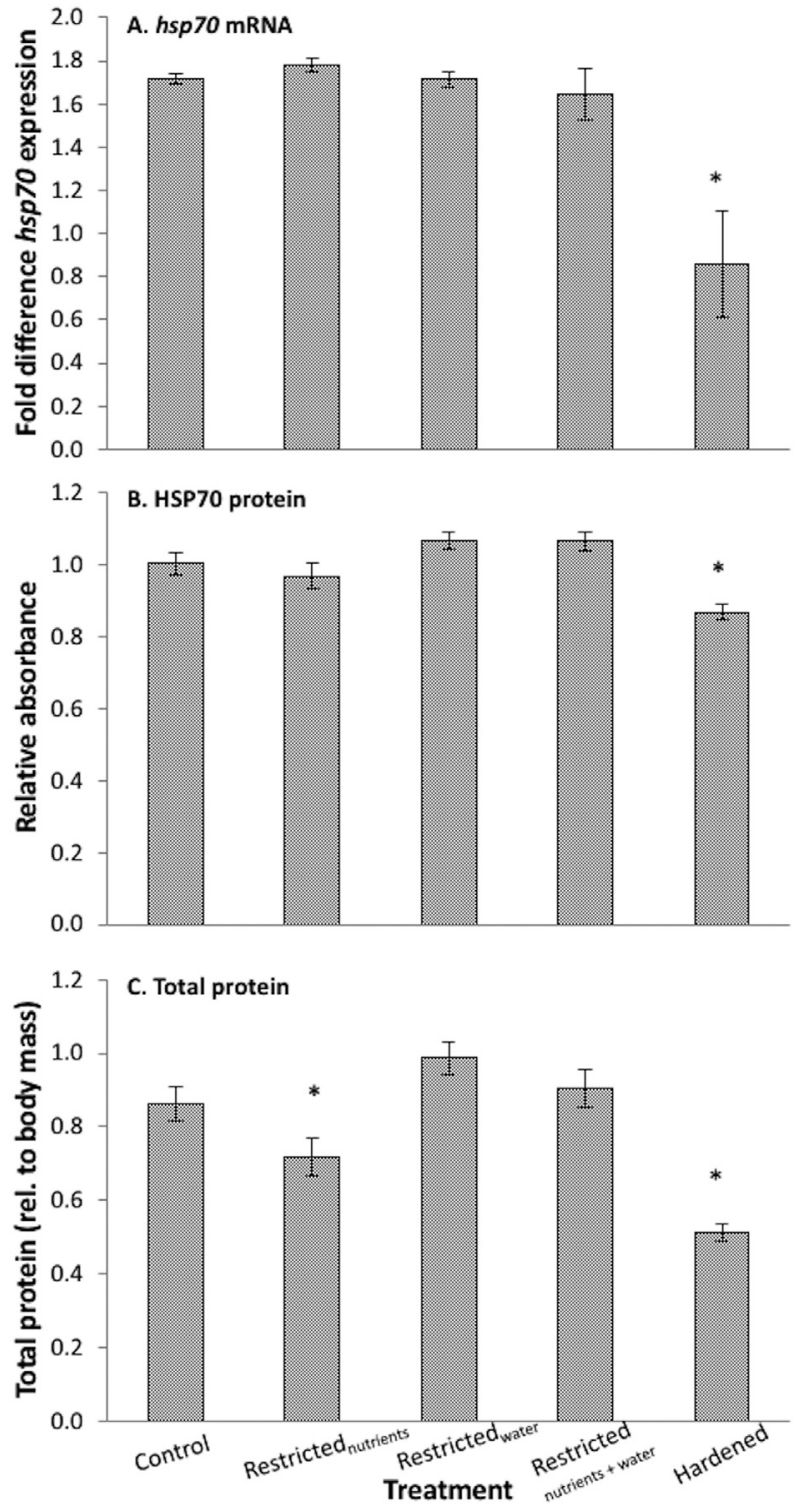

Fig. 2. Mean \pm SE (A) hsp70 mRNA and (B) HSP70 protein and (C) total protein concentration (relative to body mass) responses in Ceratitis capitata following exposure to nutrient- $\left(\right.$ Restricted $\left._{\text {nutrient }}\right)$, water- $\left(\right.$ Restricted $\left._{\text {water }}\right)$ or nutrient and water restriction (Restricted $\mathrm{d}_{\text {nutrient }}+$ water $)$ pre-treatments for $72 \mathrm{~h}$. hsp 70 mRNA expression is calculated as the fold difference in expression relative to the housekeeping gene, CcRpL13 (Scolari et al., 2012). HSP70 protein levels are expressed as relative absorbance of HSP70 to the blank sample, scaled by the grand plate mean (as per Sørensen et al., 2013). * indicates significant difference from control group at $\mathrm{p}=0.05$.

mechanisms that arise from prior exposure to a different stressor (e.g. Sinclair et al., 2013) is specific to the stress experienced, while the genetic background of the population is also known to substantially influence results (see e.g. Telonis-Scott et al., 2016). However, it is rare for all three mechanisms to be examined simultaneously within the same individuals, let alone across multiple stressors in the same population. As environmental stressors are likely to occur in concert, understanding the causal relationship between these traits and stress correlations is imperative.

In contrast with other studies, in our study pre-treatment had no effect on chill coma recovery time (e.g. Hoffmann et al., 2005). This was particularly noteworthy considering significant changes were detected in body water and body lipid content in the different groups for both traits (Table 2). As desiccation-related mortality has been shown to occur between 70 and $80 \mathrm{~h}$ under the same conditions in this study (Weldon et al., 2016), and the gut contents are empty after $48 \mathrm{~h}$ of fasting (Nyamukondiwa and Terblanche, 2009), we are confident that depletion of lipid and water stores associated with body condition was readily induced by our treatments. This can be confirmed by the leth-

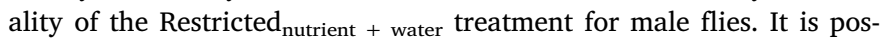
sible that each individual's condition, such as starting lipid and water levels, may have been a more important factor than the treatment individuals experienced. However, as the measurements for lipid and water levels are destructive and cannot be assayed ahead of time, we cannot confirm this. Therefore, while hydration and nutritional state may contribute to the underlying chill coma recovery response, potentially by regulating ion concentration through compensatory water intake (e.g. Raubenheimer and Gäde, 1993), this study shows that the expected changes in water and nutrition levels from our treatments do not translate into a measurable difference in chill coma recovery time in C. capitata (Fig. 1A).

Heat knockdown time showed significant and complex responses to the pre-treatment stressors that, in some cases, were sex-specific. For example, the significant reduction of heat knockdown time in females

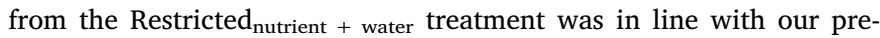
dictions and highlights the potential physiological costs of encountering multiple simultaneous environmental stressors. That we did not find the same response in male flies is likely due to the small sample size as-

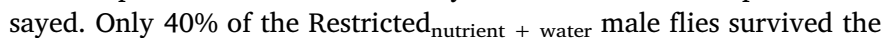
pre-treatment to be assayed so the tolerance estimates gained from these flies must be examined with caution. The female flies are likely to better represent the effect of combined nutrition and hygric stress on heat knockdown time in this species.

The improved heat knockdown time in the Restricted nutrient $_{\text {flies was }}$ not anticipated and may be an artefact of increased (compensatory) water uptake during this stress. Evaporative cooling might be enhanced due to larger water reserves but is considered unlikely to be a major mechanism employed by Dipterans due to their small body size and limited body water reserves (Chown and Nicholson, 2004 but see e.g. Weldon et al., 2016). Survival time under hot, dry conditions might also be extended if body water content is higher. In contrast to predictions of some theoretical tolerance models (e.g. Rezende et al., 2011), water restriction did not significantly reduce heat tolerance, a result that is in keeping with similar work on Drosophila (Overgaard et al., 2012). However, in Overgaard et al. (2012), study flies were provided with a nutritive source during acclimation and may thus have been compensating for reductions in body water content through increased feeding. In many insects, the sensations of 'hunger' and 'thirst' are closely associated and an absence of one resource can result in overcompensation of the other (e.g. Raubenheimer and Gäde, 1993). This, together with the positive association between body water content and heat knockdown time, indicates that greater body water content enhances heat resistance.

Metabolising lipid stores may also produce body water in insects, as suggested previously for this species (Weldon et al., 2016) and could explain the ability of the desiccated flies to better tolerate the heat stress. However, we could not determine if flies were metabolising lipid stores as we were only able to calculate body lipid content after heat knockdown time was estimated. Also, it was not possible to ascertain the compositional change in lipids that could have occurred as a consequence of membrane saturation. As the combination stress treatment had the lowest heat knockdown time of all treatment groups, it is likely that both hydration status and lipid content are important in mediating heat tolerance in C. capitata, perhaps through reducing lipid stores available to be metabolised for water (e.g. Weldon et al., 2016). This synergistic effect could explain the significantly greater impact of the combination treatment on heat knockdown time.

While the expression of heat shock proteins has been suggested as a potential plastic mechanism underlying improved heat tolerance, we found no evidence of beneficial Hsp70 responses in C. capitata to nutrient and water restriction in C. capitata. This is not unexpected following prolonged exposure to stress. Since the benefits of heat shock 
Table 3

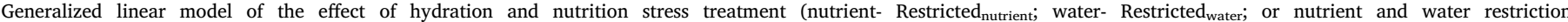

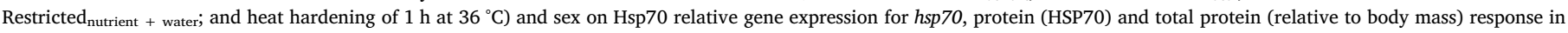
Ceratitis capitata. Factors in bold indicate significance at $\mathrm{p}=0.05$.

\begin{tabular}{|c|c|c|c|c|c|}
\hline & & Wald's $\chi^{2}$ & SE & $\mathrm{t}$ & $\mathrm{p}$ \\
\hline \multirow[t]{2}{*}{ hsp70 mRNA } & Intercept & 1.711 & 0.135 & 12.701 & $<0.001$ \\
\hline & Restricted $_{\text {nutrient }}$ & 0.101 & 0.190 & 0.529 & 0.603 \\
\hline $\mathrm{AIC}=$ & Restricted $_{\text {water }}$ & 0.037 & 0.190 & 0.196 & 0.847 \\
\hline \multirow[t]{7}{*}{7.575} & Restricted $_{\text {nutrient }}+$ water & 0.035 & 0.190 & 0.181 & 0.858 \\
\hline & Hardening & -1.070 & 0.213 & -5.024 & $<0.001$ \\
\hline & Sex & 0.012 & 0.190 & 0.064 & 0.950 \\
\hline & Restricted $_{\text {nutrient }} \times$ sex & -0.072 & 0.269 & -0.268 & 0.792 \\
\hline & Restricted $_{\text {water }} \times$ sex & -0.081 & 0.269 & -0.299 & 0.768 \\
\hline & Restricted $_{\text {nutrient }+ \text { water }} \times$ sex & -0.217 & 0.269 & -0.805 & 0.431 \\
\hline & Hardening $\times$ sex & 0.429 & 0.301 & 1.423 & 0.172 \\
\hline \multirow[t]{2}{*}{ HSP70 protein } & Intercept & 1.008 & 0.040 & 25.073 & $<0.001$ \\
\hline & Restricted $_{\text {nutrient }}$ & -0.060 & 0.057 & -1.048 & 0.301 \\
\hline $\mathrm{AIC}=$ & Restricted $_{\text {water }}$ & 0.034 & 0.057 & 0.594 & 0.556 \\
\hline \multirow[t]{7}{*}{-84.230} & Restricted $_{\text {nutrient }}+$ water & 0.090 & 0.057 & 1.579 & 0.123 \\
\hline & Hardening & -0.150 & 0.060 & -2.481 & 0.018 \\
\hline & Sex & -0.008 & 0.057 & -0.144 & 0.886 \\
\hline & Restricted $_{\text {nutrient }} \times$ sex & 0.048 & 0.080 & 0.599 & 0.553 \\
\hline & Restricted $_{\text {water }} \times$ sex & 0.059 & 0.080 & 0.729 & 0.471 \\
\hline & Restricted $_{\text {nutrient }}+$ water $\times$ sex & -0.058 & 0.080 & -0.719 & 0.477 \\
\hline & Hardening $\times$ sex & 0.025 & 0.085 & 0.295 & 0.769 \\
\hline \multirow[t]{2}{*}{ Total protein } & Intercept & 0.804 & 0.059 & 13.528 & $<0.001$ \\
\hline & Restricted $_{\text {nutrient }}$ & -0.025 & 0.084 & -0.293 & 0.771 \\
\hline $\mathrm{AIC}=$ & Restricted $_{\text {water }}$ & 0.087 & 0.084 & 1.038 & 0.306 \\
\hline \multirow[t]{7}{*}{-46.706} & Restricted $_{\text {nutrient }}+$ water & 0.111 & 0.084 & 1.321 & 0.195 \\
\hline & Hardening & -0.341 & 0.089 & -3.824 & $<0.001$ \\
\hline & Sex & 0.116 & 0.084 & 1.376 & 0.177 \\
\hline & Restricted $_{\text {nutrient }} \times$ sex & -0.239 & 0.119 & -2.007 & 0.052 \\
\hline & Restricted $_{\text {water }} \times$ sex & 0.075 & 0.119 & 0.633 & 0.531 \\
\hline & Restricted $_{\text {nutrient }}+$ water $\times$ sex & -0.139 & 0.119 & -1.167 & 0.251 \\
\hline & Hardening $\times$ sex & -0.019 & 0.126 & -0.150 & 0.882 \\
\hline
\end{tabular}

protein are typically lost after more than an hour of upregulation, as seen in reduced fitness and survival accompanying over-expression (e.g. Feder et al., 1992; Silbermann and Tatar, 2000) and even $\mathrm{CT}_{\max }$ estimates (Sørensen et al., 2013). Previous assays of HSP70 protein and hsp70 mRNA expression in C. capitata have shown the expected timecourse of induction following short exposures to stressful temperatures as compared to D. melanogaster (HSP70 protein, Stephanou et al., 1983; hsp70 mRNA, Kalosaka et al., 2009), but showed no association in our study. Our hardening treatment was based upon the conditions used in Kalosaka et al. (2009); however, this study did not include a housekeeping gene as control, as is common practice, but instead expressed hsp70 mRNA levels relative to the highest values recorded in their study, which occurred in larval tissue. These key methodological differences may limit the analytical power of drawing comparisons across studies. Another study not focussed directly on heat shock also found little association of hsp70 mRNA expression and stress in C. capitata (Pujol-Lereis et al., 2014), highlighting the importance of considering other cellular stress response mechanisms (Lester and Greenwood, 1997; Salvucci et al., 2000). The importance of the heat shock response in Ceratitis species under different environmental conditions therefore requires further investigation to determine the mechanisms and potential interaction effects with other tolerance traits. As Ceratitis spp. show different effects of methodological context (i.e. rates of thermal change) on $\mathrm{CT}_{\max }$ estimates and phenotypic plasticity in comparison to D. melanogaster (Chown et al., 2009; Nyamukondiwa and Terblanche, 2010; Mitchell et al., 2011), it is likely that the cellular or physiological mechanisms underlying heat tolerance in Ceratitis are also different.

Previous work on C. capitata has found that starvation significantly reduced heat tolerance when estimated as the critical thermal maximum ( $\mathrm{CT}_{\max }$; Nyamukondiwa and Terblanche, 2009). The variation in results between studies is likely a consequence of the lack of congruence between different measures of thermal tolerances (e.g. Hoffmann et al., 1997). These study-specific patterns of response would indicate that a trade-off likely exists between water balance and nutritional status but is being masked to some extent by the measures and treatment conditions chosen for each study. This may also be the case for sex differences in thermal tolerance traits. Potential differences in composition in body water and body lipid content between the sexes may have been lost after standardising to lean (lipid and water removed) body mass, removing the normal sex-specific compositional differences that were still evident in thermal tolerance estimates. Accounting for differences in overall body size using the lean mass was the most accurate method of standardising due to the variation in mass induced by the pre-treatments.

\section{Conclusions}

Despite an extensive body of evidence of cross-tolerance and nutrient and water restriction on estimates of thermal tolerance, particularly for cold tolerance traits (e.g. Bubliy et al., 2012a; Bubliy et al., 2012b), we found no positive correlation between nutrition and desiccation stress and cold tolerance in $C$. capitata but i) a positive association between nutrient restriction and heat tolerance and ii) a negative association with the combined nutrient and water restriction for heat knockdown time. This indicates that the physiological impact of long term, prior stress is different to the stress induced by tolerance assays, and potentially also from stressors encountered under natural conditions. The heat tolerance trait we measured here was also not influenced greatly by the Hsp70 stress response commonly seen in many other insect species (Feder and Hofmann, 1999). As prolonged exposure to xeric conditions, as well as sporadic availability of food resources, are likely to be common in heterogeneous landscapes, the impact of long-term reduction in water availability and declines in nutritional status using a multi-traits approach requires further attention, particularly considering forecast global environmental change.

Supplementary data to this article can be found online at http://dx. 
doi.org/10.1016/j.cbpa.2017.06.019.

\section{Acknowledgements}

The authors thank Janina von Diest for early technical assistance, Dr. Aruna Manrankhan at CRI for providing specimens, the Central Analytical Facility at Stellenbosch University for assistance with RTPCR analysis, the Biochemistry Department for access to plate reader for HSP70 protein absorbance and the anonymous referees that provided constructive criticism of an earlier version of this manuscript. KAM was supported by the Claude Leon foundation. LB was supported by an NRF Innovation Fellowship. JST and KAM are supported by HortGro Science. SCT and JST are supported by different National Research Foundation Incentive Funding for Rated (IFR) researchers' schemes. The authors declare no conflict of interest.

\section{References}

Addo-Bediako, A., Chown, S.L., Gaston, K.J., 2000. Thermal tolerance, climatic variability and latitude. Proc. Biol. Sci. B 267, 739-745.

Benoit, J.B., Lopez-Martinez, G., Elnitsky, M.A., Lee Jr., R.E., Denlinger, D.L., 2009. Dehydration-induced cross tolerance of Belgica antarctica larvae to cold and heat is facilitated by trehalose accumulation. Comp. Biochem. Physiol. A 152, 518-523.

Boardman, L., Sørensen, J.G., Terblanche, J.S., 2013. Physiological responses to fluctuating thermal and hydration regimes in the chill susceptible insect, Thaumatotibia leucotreta. J. Insect Physiol. 59, 781-794.

Boardman, L., Sørensen, J.G., Terblanche, J.S., 2015. Physiological and molecular mechanisms associated with cross tolerance between hypoxia and low temperature in Thaumatotibia leucotreta. J. Insect Physiol. 82, 75-84.

Bubliy, O.A., Kristensen, T.N., Kellermann, V., Loeschcke, V., 2012a. Plastic responses of four environmental stresses and cross-resistance in a laboratory population of Drosophila melanogaster. Funct. Ecol. 26, 245-253.

Bubliy, O.A., Kristensen, T.N., Kellermann, V., Loeschcke, V., 2012b. Humidity affects genetic architecture of heat resistance in Drosophila melanogaster. J. Evol. Biol. 25, 1180-1188.

Carey, J.R., Liedo, P., Müller, H.-G., Wang, J.-L., Chiou, J.-M., 1998. Relationship of age patterns of fecundity to mortality, longevity, and lifetime reproduction in a large cohort of Mediterranean fruit fly females. J. Gerontol. Biol. Sci. 53A, B245-B251.

Chown, S.L., Nicholson, S.W., 2004. Insect Physiological Ecology: Mechanisms and Patterns. Oxford University Press, Oxford.

Chown, S.L., Terblanche, J.S., 2006. Physiological diversity in insects: ecological and evolutionary contexts. Adv. Insect Physiol. 33, 50-152.

Chown, S.L., Jumbam, K.R., Sørensen, J.G., Terblanche, J.S., 2009. Phenotypic variance, plasticity and heritability estimates of critical thermal limits depend on methodological context. Funct. Ecol. 23, 133-140.

Clusella-Trullas, S., Boardman, L., Faulkner, K.T., Peck, L.S., Chown, S.L., 2014. Effects of temperature on heat-shock responses and survival of two species of marine invertebrates from sub-Antarctic Marion Island. Antarct. Sci. 26, 145-152.

Coello Alvarado, L.E., MacMillan, H.A., Sinclair, B.J., 2015. Chill-tolerant Gryllus crickets maintain ion balance at low temperatures. J. Insect Physiol. 77, 15-25.

Cooper, B.S., Williams, B.H., Angilletta Jr., M.J., 2008. Unifying indices of heat tolerance in ectotherms. J. Therm. Biol. 33, 320-323.

De Meyer, M., Robertson, M.P., Peterson, A.T., Mansell, M.W., 2008. Ecological niches and potential geographic distributions of Mediterranean fruit fly (Ceratitis capitata) and Natal fruit fly (Ceratitis rosa). J. Biogeogr. 35, 270-281.

Feder, M.E., Hofmann, G.E., 1999. Heat-shock proteins, molecular chaperones, and the stress response: evolutionary and ecological physiology. Annu. Rev. Physiol. 61, 243-282.

Feder, J.H., Rossi, J.M., Solomon, J., Solomon, N., Lindquist, S., 1992. The consequences of expressing Hsp70 in Drosophila cells at normal temperatures. Genes Dev. 6, 1402-1413.

Fischer, K., Dierks, A., Franke, K., Geister, T.L., Liszka, M., Winter, S., Pflicke, C., 2010. Environmental effects on temperature stress resistance in the tropical butterfly Bicyclus anynana. PLoS One e15284.

Hoffmann, A.A., Harshman, L.G., 1999. Desiccation and starvation resistance in Drosophila: patterns of variation at the species, population and intrapopulation levels. Heredity 83, 637-643.

Hoffmann, A.A., Dagher, H., Hercus, M., Berrigan, D., 1997. Comparing different measures of heat resistance in selected lines of Drosophila melanogaster. J. Insect Physiol. 43, 393-405.

Hoffmann, A.A., Sørensen, J.G., Loeschcke, V., 2003. Adaptation of Drosophila to temperature extremes: bringing together quantitative and molecular approaches. J. Therm. Biol. 28, 175-216.

Hoffmann, A.A., Hallas, R., Anderson, A.R., Telonis-Scott, M., 2005. Evidence for a robust sex-specific trade-off between cold resistance and starvation resistance in Drosophila melanogaster. J. Evol. Biol. 18, 804-810.

Kalosaka, K., Soumaka, E., Politis, N., Mintzas, A.C., 2009. Thermotolerance and HSP70 expression in the Mediterranean fruit fly Ceratitis capitata. J. Insect Physiol. 55, 568-573.

Karl, I., Becker, M., Hinzke, T., Mielke, M., Schiffler, M., Fischer, K., 2014. Interactive effects of acclimation temperature and short-term stress exposure on resistance traits in the butterfly Bicyclus anynana. Physiol. Entomol. 39, 222-228.

Kearney, M.R., Simpson, S.J., Raubenheimer, D., Kooijman, S.A.L.M., 2013. Balancing heat, water and nutrients under environmental change: a thermodynamic niche framework. Funct. Ecol. 27, 950-965.

Kellermann, V., Overgaard, J., Loeschcke, V., Kristensen, T.N., Hoffmann, A.A., 2013. Trait associations across evolutionary time within a Drosophila phylogeny: correlated selection or genetic constraint? PLoS One e72072.

Lester, P.J., Greenwood, D.R., 1997. Pretreatment induced thermotolerance in Lightbrown apple moth, (Lepidoptera: Tortricidae) and associated induction of heat shock protein synthesis. J. Econ. Entomol. 90, 199-204.

Malacrida, A.R., Gomulski, L.M., Bonizzoni, M., Bertin, S., Gasperi, G., Guglielmino, C.R., 2007. Globalization and fruitfly invasion and expansion: the medfly paradigm. Genetica 131, 1-9.

McCue, M.D., 2010. Starvation physiology: reviewing the different strategies animals use to survive a common challenge. Comp. Biochem. Physiol. A 156, 1-18.

Mellanby, K., 1932. The influence of atmospheric humidity on the thermal death point of a number of insects. J. Exp. Biol. 9, 222-231.

Mitchell, K.A., Sgró, C.M., Hoffmann, A.A., 2011. Phenotypic plasticity in upper thermal limits is weakly related to Drosophila species distributions. Funct. Ecol. 25, 661-670.

Nyamukondiwa, C., Terblanche, J.S., 2009. Thermal tolerance in adult Mediterranean and Natal fruit flies (Ceratitis capitata and Ceratitis rosa): effects of age, gender and feeding status. J. Therm. Biol. 34, 406-414.

Nyamukondiwa, C., Terblanche, J.S., 2010. Within-generation variation in critical thermal limits in adult Mediterranean and Natal fruit flies Ceratitis capitata and Ceratitis rosa: thermal history affects short-term responses to temperature. Physiol. Entomol. 35, 255-264.

Nyamukondiwa, C., Kleynhans, E., Terblanche, J.S., 2010. Phenotypic plasticity of thermal tolerance contributes to the invasion potential of Mediterranean fruit flies (Ceratitis capitata). Ecol. Entomol. 35, 565-575.

Olsson, T., MacMillan, H.A., Nyberg, N., Staerk, D., Malmendal, A., Overgaard, J., 2016. Hemolymph metabolites and osmolality are tightly linked to cold tolerance of Drosophila species: a comparative study. J. Exp. Biol. 219, 2504-2513.

Overgaard, J., MacMillan, H.A., 2017. The integrative physiology of insect chill tolerance. Annu. Rev. Physiol. 79, 187-208.

Overgaard, J., Kristensen, T.N., Sørensen, J.G., 2012. Validity of thermal ramping assays used to assess thermal tolerance in arthropods. PLoS One 7, e32758.

Papadimitriou, E., Kritikou, D., Mavroidis, M., Zacharaopoulou, A., Mintzas, A.C., 1998 The heat shock 70 gene family in the Mediterranean fruit fly Ceratitis capitata. Insect Mol. Biol. 7, 279-290.

Pujol-Lereis, L.M., Rabossi, A., Quesada-Allué, L.A., 2014. Analysis of survival, gene expression and behavior following chill-coma in the medfly Ceratitis capitata: effects of population heterogeneity and age. J. Insect Physiol. 71, 156-163.

R core team, 2013. R: A Language and Environment for Statistical Computing. (Vienna, Austria. http://www.R-project.org/).

Raubenheimer, D., Gäde, G., 1993. Compensatory water intake by locusts (Locusta migratoria): implications for mechanisms regulating drink size. J. Insect Physiol. 39, 275-281.

Rezende, E.L., Tejedo, M., Santos, M., 2011. Estimating adaptive potential of critical thermal limits: methodological problems and evolutionary implications. Funct. Ecol. $25,111-121$

Salvucci, M.E., Stecher, D.S., Henneberry, T.J., 2000. Heat shock proteins in whiteflies, an insect that accumulates sorbitol in response to heat stress. J. Therm. Biol. 25, $363-371$.

Scharf, I., Wexler, Y., MacMillan, H.A., Presman, S., Simon, E., Rosenstein, S., 2016. The negative effect of starvation and the positive effect of a mild thermal stress on thermal tolerance of the red flour beetle, Tribolum castaneum. Sci. Nat. 103, 20.

Scolari, F., Gomulski, L.M., Ribeiro, J.M., Siciliano, P., Meraldi, A., Falchetto, M., Bonomi, A., Manni, M., Gabrieli, P., Malovini, A., Bellazzi, R., Aksoy, S., Gasperi, G., Malacrida, A.R., 2012. Transcriptional profiles of mating-response genes from testes and male accessory glands of the Mediterranean fruit fly, Ceratitis capitata. PLoS One 7, e46812.

Shelly, T.E., Kennelly, S.S., 2003. Starvation and the mating success of wild male Mediterranean fruit flies (Diptera: Tephritidae). J. Insect Behav. 16, 171-179.

Silbermann, R., Tatar, M., 2000. Reproductive costs of heat shock protein in transgenic Drosophila melanogaster. Evolution 54, 2038-2045.

Sinclair, B.J., Roberts, S.P., 2005. Acclimation, shock and hardening in the cold. J. Therm. Biol. 30, 557-562.

Sinclair, B.J., Ferguson, L.V., Salehipour-Shirazi, G., MacMillan, H.A., 2013. Cross-tolerance and cross-talk in the cold: relating low temperatures to desiccation and immune stress in insects. Integr. Comp. Biol. 53, 545-556.

Sørensen, J.G., Holmstrup, M., 2011. Cryoprotective dehydration is widespread in Arctic springtails. J. Insect Physiol. 57, 1147-1153.

Sørensen, J.G., Loeschcke, V., Kristensen, T.N., 2013. Cellular damage as induced by high temperature is dependent on rate of temperature change - investigating consequences of ramping rates on molecular and organismal phenotypes in Drosophila melanogaster. J. Exp. Biol. 216, 809-814.

Stephanou, G., Alahiotis, S.N., Marmaras, V.J., Christodoulou, C., 1983. Heat shock response in Ceratitis capitata. Comp. Biochem. Physiol. B 74, 425-432.

Telonis-Scott, M., Sgrò, C.M., Hoffmann, A.A., Griffin, P.C., 2016. Cross-study comparison reveals common genomic, network, and functional signatures of desiccation resistance in Drosophila melanogaster. Mol. Biol. Evol. 33, 1053-1067.

Terblanche, J.S., Clusella-Trullas, S., Deere, J.A., Chown, S.L., 2008. Thermal tolerance in a south-east African population of the tsetse fly Glossina pallidipes (Diptera, Glossinidae): implications for forecasting climate change impacts. J. Insect Physiol. 54, 114-127. 
Terblanche, J.S., Hoffmann, A.A., Mitchell, K.A., Rako, L., le Roux, P.C., Chown, S.L., 2011. Ecologically relevant measures of tolerance to potentially lethal temperatures. J. Exp. Biol. 214, 3713-3725.

Weldon, C.W., Terblanche, J.S., Chown, S.L., 2011. Time-course for attainment and reversal of acclimation to constant temperature in two Ceratitis species. J. Therm. Biol. 36, 479-485.

Weldon, C.W., Boardman, L., Marlin, D., Terblanche, J.S., 2016. Physiological mechanisms of dehydration tolerance contribute to invasion potential in Ceratitis capitata
(Wiedemann) (Diptera: Tephritidae) relative to its less widely distributed congeners. Front. Zool. 13, 15

Winston, P.W., Bates, D.H., 1960. Saturated solutions for the control of humidity in biological research. Ecology 41, 232-237.

Zachariassen, K.E., 1985. Physiology of cold tolerance in insects. Physiol. Rev. 65, 799-832.

Zera, A.J., Harshman, L.G., 2001. The physiology of life history trade-offs in animals. Annu. Rev. Ecol. Syst. 32, 95-126. 